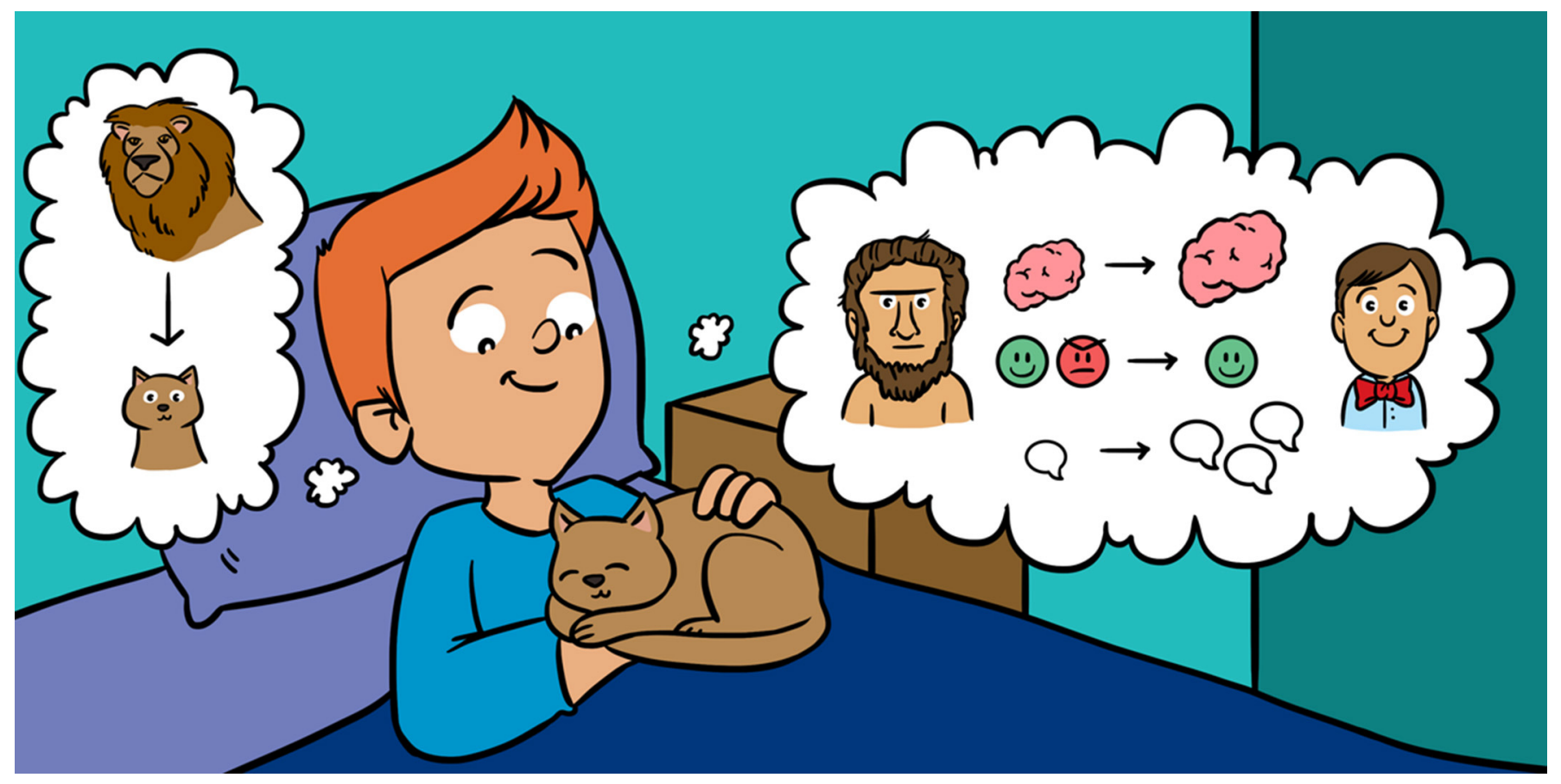

\title{
ARE HUMANS MORE LIKE WOLVES OR DOGS?
}

\author{
Mati Breski ${ }^{1 *}$ and Daniel Dor ${ }^{2}$ \\ ${ }^{1}$ School of Philosophy, Linguistics and Science Studies, Tel Aviv University, Tel Aviv, Israel \\ ${ }^{2}$ Department of Communication, Tel Aviv University, Tel Aviv, Israel
}

YOUNG REVIEWERS: YITZHAK NAVON SCHOOL YOKNE'AM AGES: $11-12$
What makes humans a unique species? How did ancient humans evolve to live together and cooperate with each other? Research on the evolution of prehistoric humans shows that we have some characteristics in common with domesticated animals, like dogs, cows, and pigs. These similarities led researchers to propose that the human species has also undergone a type of domestication, which decreased our aggression and increased our social nature. In this article, we examine this idea and present an alternative: that the human species did not become domesticated like pets or farm animals, but instead evolved the ability to control its emotions, similar to other highly social species, like wolves. Emotional control allows us to restrain our aggression or promote it, depending on the situation. We think that emotional control is what allowed the human species to develop unique ways of communication in the animal kingdom.

\section{WHAT IS DOMESTICATION?}

Maybe you have a cat, a dog, or another pet in your home, or maybe you live in a rural area with farm animals, like horses, cows, 
Figure 1

Domesticated species evolved from wild species, and many domesticated species share characteristics with each other. Here you can see a wild boar next to a domesticated pig, and a wolf next to a domesticated dog.

Notice how both domesticated species are smaller than the wild species, have smaller heads, rounder faces, and more depigmentation of the fur (Image credit: Hadas Breski-Kalai).

\section{EVOLUTION}

A change in the characteristics of living creatures from one generation to the next.

\section{DOMESTICATION}

The process by which wild species are adapted to the human environment, by decreasing their fear and aggression toward humans, until the animals become a new species.

\section{DOMESTICATION SYNDROME}

A collection of physical and behavioral characteristics that occur in most domesticated animals and make them different from the wild species they came from.

\section{DEPIGMENTATION}

The creation of less color pigments than usual, causing light colors to appear on an animal's skin and/or fur

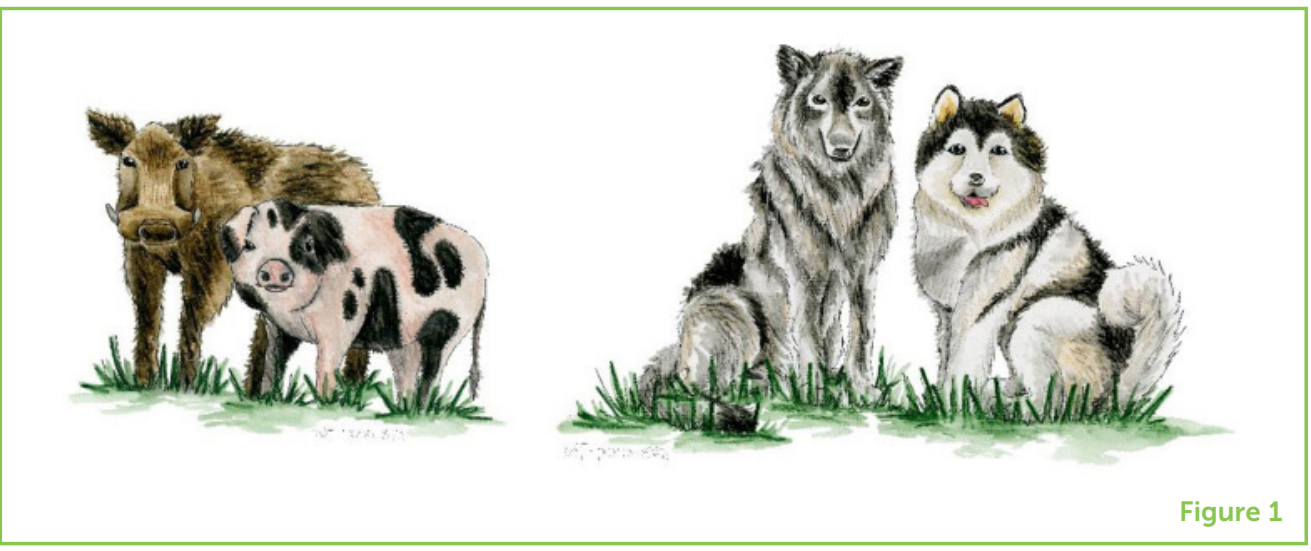

and chickens. Did you know that the great-great ancestors of these animals were wild species living in nature, until they met humans? During the course of evolution, humans have influenced wild species like wolves and wild oxen in many ways, sometimes on purpose and other times accidentally. As a result of human influence, new species like dogs and cattle evolved from those wild species. These new species had less fear of humans and showed less aggression toward them. The evolutionary process of turning wild animals into new species that are adapted to living in the human environment is called domestication.

When comparing domesticated species to the wild species from which they developed, we see that most types of domesticated animals have some characteristics in common with each other, making them different from the wild, pre-domesticated species. These common characteristics are called domestication syndrome. For example, have you noticed that dogs, cows, and horses often have white or brown fur patches on their faces, or white spots along their bodies? This is called depigmentation and it comes from a decrease in the amounts of pigments (color molecules) in the fur (Figure 1). Other changes in the appearance of domesticated species include smaller skull size, a rounder and more female-like skull shape, floppy ears, and smaller teeth and brains. Domestication syndrome also includes changes in reproductive cycles. For example, a female wolf can mate and become pregnant only between January and April, but a female dog can become pregnant about twice a year.

\section{DID DOMESTICATION SYNDROME HAPPEN IN HUMANS?}

Modern humans (Homo sapiens) evolved from other human species, including Homo erectus and Homo neanderthalensis. For more information read the Young Minds article A Brief Account of Human Evolution for Young Minds [1]. When Homo sapiens are compared with these older species, some characteristics are seen that look a bit like 
SELF-

\section{DOMESTICATION}

A process in which species are domesticated without direct interference of an external domesticator. Some researchers argue that humans have gone through this process during their evolution. domestication syndrome. For example, human skulls have become smaller and more rounded over evolution, and a more female-like face structure is now common. Also, the area around the pupil in the eyes of human species has slowly become depigmented, creating the "whites" of our eyes. Against the eyes' white background, it is easier to notice the movement of the pupils, which helps humans communicate non-verbally, using the direction of the gaze [2].

Other types of bodily communication developed in human species, including gestures like pointing with a finger toward an object of interest, or body movements like stamping the foot to express anger. Human species also produce sounds that are not words but still help with communication, such as imitating the roar of a lion to point out something scary. All these actions separate humans from the rest of the animal kingdom. Research shows that humans communicate and collaborate in ways that are much more advanced than those of their distant relatives, like the chimpanzees [3]. Where did these enhanced abilities come from? Some scientists believe that humans evolved to be less aggressive and friendlier, just like the domesticated species that they created! That is, humans have undergone a process of self-domestication. During self-domestication, group members who were too aggressive, or who did not collaborate, were dismissed from the group and therefore did not survive to have children. Back then, it was almost impossible to live on your own, or find someone to mate and have offspring with. This is similar to the way humans domesticated other animals: they banished individuals that were aggressive and mated only the most obedient, mild-tempered, friendly individuals with one another.

\section{UNIQUE FEATURES OF HUMAN EVOLUTION}

Although some of the evolutionary changes seen in Homo sapiens resemble those of domestication syndrome, there are also crucial differences. For example, human evolution led to a clear increase in brain size. This change makes human evolution different from domestication because, in most domesticated species, brain size decreased compared to the wild species from which they evolved. Another significant difference is found in social structure. During domestication, wild species went from living in groups with complex social interactions to living more isolated and simple lives. For example, compare the wolf and the dog: wolves live in packs and cooperate for hunting and raising their offspring. The ability of domesticated dogs to cooperate for purposes of hunting or raising offspring has decreased during evolution.

In contrast, in human species, social complexity has increased over the course of evolution. Greater levels of collaboration and communication have allowed humans to live in larger and larger groups and to create a division of labor, in which some members 
Figure 2

Ways of obtaining food, the amount of help the mother receives in raising her offspring, and the levels of social cooperation differ significantly between domestic dogs and wild wolves. However, similarities in these characteristics exist between packs of wolves and groups of humans.

\section{REACTIVE}

\section{AGGRESSION}

An aggressive behavior occurring in reaction to a certain irritation.

\section{PROACTIVE}

\section{AGGRESSION}

An aggressive behavior that is planned in advance, not in response to an action of the attacked side.

\begin{tabular}{|l|l|l|l|}
\hline & Together & Rrom humans \\
\hline $\begin{array}{l}\text { How is food } \\
\text { obtained? }\end{array}$ & Together & $\begin{array}{l}\text { The entire pack - males } \\
\text { and other females }\end{array}$ & $\begin{array}{l}\text { Rare help from male } \\
\text { parent }\end{array}$ \\
\hline $\begin{array}{l}\text { Whothelps the } \\
\text { offspring? }\end{array}$ & $\begin{array}{l}\text { Group members, } \\
\text { especially close } \\
\text { family }\end{array}$ & $\begin{array}{l}\text { Cooperate well with } \\
\text { humans, the pack hunts } \\
\text { together }\end{array}$ & $\begin{array}{l}\text { Cooperate well with } \\
\text { humans, but struggle } \\
\text { to hunt together }\end{array}$ \\
\hline $\begin{array}{l}\text { How much } \\
\text { social } \\
\text { cooperation? }\end{array}$ & $\begin{array}{l}\text { Much higher than } \\
\text { other apes }\end{array}$ & & \\
\hline
\end{tabular}

Figure 2

gather fruits and vegetables, others hunt, and those who stay in camp keep the fire burning, for example. Collaboration and communication have also led humans to help each other raise offspring, create complex tools, and pass important knowledge on to future generations, among other achievements. When we look at it this way, humans seem more like a pack of wolves than like a collection of domesticated dogs (Figure 2). Thanks to their social abilities, humans have spread across the globe and harnessed the power of nature for their needs. This success of human species resulted from the ability of individuals to be mild-tempered and friendly toward one another, so that they could live together as a group. But is there more to the story?

\section{AN ALTERNATIVE EXPLANATION: EVOLUTION OF INCREASED EMOTIONAL CONTROL}

When we examine human history and studies comparing human behavior to that of other apes, we see that humans can be the most aggressive and violent species in the animal kingdom. On one hand, humans show a lower reactive aggression compared with chimpanzees - meaning we can restrain ourselves when we are angry. But, on the other hand, humans show a higher tendency for proactive aggression [4]. This means that we can plan and initiate aggressive behavior toward other people. So, in contrast to domesticated species whose aggressive tendencies became reduced, the aggressive tendencies of human species became better controlled (Figure 3).

The ability of humans to control their aggression comes from a more general ability to control all emotional responses. Evolution of an increased amount of emotional control can also explain some of the 
Figure 3

(A) In

self-domestication, "angry" individuals with a tendency for aggression are dismissed from the group and therefore cannot pass on their genes. Over tens of thousands of years, since only the "good" individuals remain to reproduce, the population becomes more domesticated. (B) An increase in brain size may have helped humans to evolve the complexity needed to better control impulses and emotions.

Emotional control allows humans to be friendly toward group members or aggressive toward strangers, depending on the situation.
(A) Self-Domestication

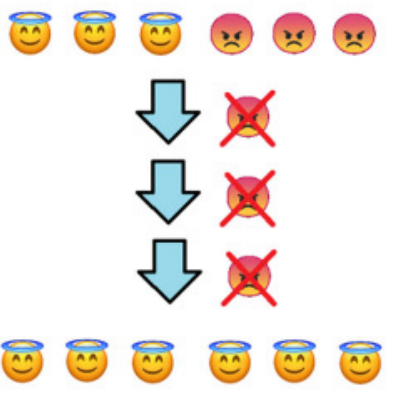

(B) Emotional Control

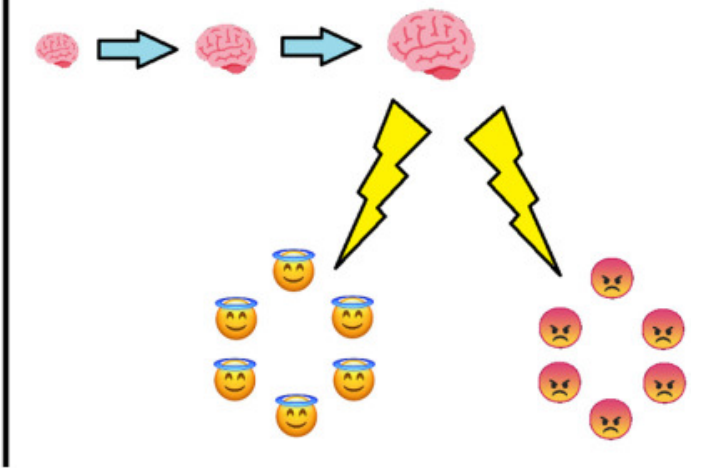

Figure 3

interesting differences between human evolution and domestication that we mentioned earlier [5]. For example, humans' increased brain size may have led to the development of brain areas involved with emotional control. The increase in social complexity seen in humans requires the ability to express or suppress certain emotions, depending on the situation. Finally, humans' varied and unique communication abilities require emotional control over the bodily actions used for communication; for example, humans must control when to have an angry facial expression or when to produce sounds of excitement. Other apes, like chimpanzees, are much less successful in controlling such behaviors.

The development of language also greatly affected the ability of evolving humans to control their emotions. For example, humans can use words to express their feelings in certain situations, which can sometimes influence what they are feeling. The next time you are taking a test or participating in a contest, try telling yourself that you are feeling excitement in your body instead of anxiety-maybe you can make your emotions more positive!

\section{SUMMARY}

Despite some similarities to domesticated species like dogs and cattle, the evolution of humans is different from that of these species, and more similar to the evolution of other social mammals, like wolves and meerkats. Humans have evolved a complex social life, which includes the use of unique and diverse communication abilities. Social complexity and human communication require increased emotional control, so that they can negotiate social interactions and coordinate a cooperative discourse. A larger brain size may contribute to the ability to control emotions. So, it seems that humans are more like wolves than like dogs - at least in terms of their evolution. Wolves also live in unified, pack-like groups in which hunting is done together and mothers get help raising offspring. Social mammals like wolves exhibit 
high levels of emotional control compared with other mammals, and it seems that evolution has also helped our species to develop the ability to better control our emotions, so that we can live and work successfully together in social groups.

\section{REFERENCES}

1. Godfraind, T., and Vercauteren Drubbel, R. 2019. A brief account of human evolution for young minds. Front Young Minds. 7:22. doi: 10.3389/Frym.2019. 00022

2. Hare, B. 2017. Survival of the friendliest: homo sapiens evolved via selection for prosociality. Annu Rev Psychol. 68:155-86. doi: 10.1146/Annurev-Psych 010416-044201

3. Rekers, Y., Haun, D. B., and Tomasello, M. 2011. Children, but not chimpanzees, prefer to collaborate. Curr Biol. 21:1756-8. doi: 10.1016/j.cub.2011.08.066

4. Wrangham, R. W. 2018. Two types of aggression in human evolution. Proc Natl Acad Sci USA. 115:245-53. doi: 10.1073/Pnas.1713611115

5. Shilton, D., Breski, M., Dor, D., and Jablonka, E. 2020. Human social evolution: self-domestication or self-control? Front Psychol. 11:134. doi: 10.3389/Fpsyg 2020.00134

SUBMITTED: 01 August 2021; ACCEPTED: 21 October 2021; PUBLISHED ONLINE: 17 November 2021.

EDITED BY: Idan Segev, Hebrew University of Jerusalem, Israel

CITATION: Breski M and Dor D (2021) Are Humans More Like Wolves or Dogs? Front. Young Minds 9:751566. doi: 10.3389/frym.2021.751566

CONFLICT OF INTEREST: The authors declare that the research was conducted in the absence of any commercial or financial relationships that could be construed as a potential conflict of interest.

COPYRIGHT @ 2021 Breski and Dor. This is an open-access article distributed under the terms of the Creative Commons Attribution License (CC BY). The use, distribution or reproduction in other forums is permitted, provided the original author(s) and the copyright owner(s) are credited and that the original publication in this journal is cited, in accordance with accepted academic practice. No use, distribution or reproduction is permitted which does not comply with these terms.

\section{YOUNG REVIEWERS}

\section{YITZHAK NAVON SCHOOL YOKNE'AM, AGES: 11-12}

Sixth grade of Yitzhak Navon School Yokne'am has 31 curious kids with wide and varied horizons. As part of language classes, we learn rhetoric, writing lectures, dramaturgy and play-writing, gender on the scale of time ("Herstory") and more. Therefore, it was only natural for us to be involved in Frontier's articles review 
process. We are grateful for the opportunity, and hope to have a positive impact on the journal's editing.

\section{AUTHORS}

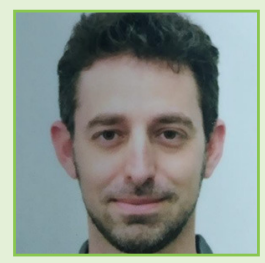

\section{MATI BRESKI}

Mati Breski is a Ph.D., student in the School of Philosophy, Linguistics, and Science Studies at Tel Aviv University. His research deals with the relationships between emotions and language during the evolution of human species. As a new parent to Mia, who was born last summer, Mati watches with excitement and curiosity as Mia's emotional, communication, and linguistic skills develop together. *matibres@gmail.com

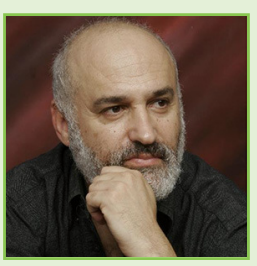

\section{DANIEL DOR}

Daniel Dor is a professor in the Department of Communication at Tel Aviv University. $\mathrm{He}$ is interested in human language and its roles in the lives of humans, and he is sure that we can understand language if we think about it in terms of human evolution-as a means of communication that we developed ourselves, with a logic similar to a social network, like Facebook or Instagram. According to his method, language belongs to the community, and each of us uses language to communicate with others, as an end user. 